\title{
ESTRUTURA VERTICAL DE UM FRAGMENTO DE FLORESTA OMBRÓFILA MISTA NO CENTRO-SUL DO PARANÁ
}

\author{
Carlos R. Sanquetta ${ }^{1}$ \\ Walquíria Pizatto ${ }^{2}$ \\ Sylvio Péllico Netto ${ }^{3}$ \\ Afonso Figueiredo Filho ${ }^{4}$ \\ Rozane de L. Eisfeld ${ }^{5}$
}

\begin{abstract}
RESUMO
Foi avaliada a estrutura vertical de um fragmento florestal com Araucaria angustifolia na região CentroSul do Paraná. O estudo foi realizado com base em parcelas amostrais permanentes, totalizando 3,5 ha, instaladas na Estação Experimental de São João do Triunfo-PR. Foram examinadas a estratificação vertical e a posição sociológica nos anos de 1995 e 1998. Utilizou-se o diagrama $h-M$ e a Posição Sociológica para representar a estratificação vertical da floresta. O diagrama dividiu a floresta em três estratos (I: altura superior a 27 m; II: entre 23 e 27 m; III: inferior a 23 m). Das 65 espécies identificadas em 1995, apenas 5 apresentaram indivíduos emergentes no estrato I. Araucaria angustifolia foi a espécie que apresentou a maior posição sociológica ( $\mathrm{PS}=24,91 \%$ ), encontrando-se distribuída nos três estratos. Nectandra grandiflora (PS $=9,80 \%$ ) foi uma espécie típica de ocorrência em dois estratos, enquanto Ilex paraguariensis ( $\mathrm{PS}=6,20 \%$ ) fez-se presente em apenas um estrato. No período de 3 anos (de 1995 a 1998) houve pouca alteração na estrutura vertical da floresta em apreço.

Palavras chave: Araucária, estratificação, posição sociológica, diagrama $h-M$
\end{abstract}

\section{VERTICAL STRUCTURE OF A FRAGMENT OF MIXED ARAUCARIA FOREST IN CENTER-SOUTH PARANA STATE, BRAZIL}

\begin{abstract}
The vertical structure of a fragment of mixed Araucaria forest, located in Center-Southern Parana State, Brazil, was analyzed. The study was based on data collection in four permanent sample plots, comprising 3.5 ha, established at the São João do Triunfo Experimental Station. The vertical stratification and the sociologic position of the component tree populations were examined for data collected in 1995 and 1998. The $h-M$ diagram and the Sociologic Position were used as reference to represent the vertical structure of the forest. The diagram divided the forest in three strata (I: tree height over $27 \mathrm{~m}$; II: 23 to $27 \mathrm{~m}$; III: less than $23 \mathrm{~m}$ ). Among the 65 species identified in the forest in 1995, only five participated in the first story (stratum I) Araucaria angustifolia was the species of greatest Sociologic Position (PS $=24.91 \%$ ), occurring in all the three strata. Nectandra grandiflora (PS $=9.80 \%$ ) was a typical species occurring in two stories, whereas Ilex paraguariensis ( $\mathrm{PS}=6.20 \%$ ) was an example of species appeared in a single story. During three years (1995 to 1998) no remarkable change was noticed in terms of vertical structure in the forest.
\end{abstract}

Key-words: Araucaria, stratification, sociologic position, $h-M$ diagram

\section{INTRODUÇÃO}

A Floresta Ombrófila Mista é um dos principais biomas brasileiros, que ocorria naturalmente em uma superfície de $200.000 \mathrm{~km}^{2}$. Esse bioma, também chamado de Floresta com Araucária, distingue-se dos demais biomas florestais brasileiros pela presença marcante do pinheiro - Araucaria angustifolia (IBGE, 1990).

\footnotetext{
${ }^{1}$ sanqueta@floresta.ufpr.br, Ph.D., Departamento de Ciências Florestais, UFPR,

M.Sc., Av. Pref. Lothário Meissner, 3400, UFPR Campus III - Jardim Botânico, Curitiba-PR, 80.210-170

3 pellico@rla13.puc.pr, Dr., Centro de Ciências Agrárias e Ambientais, PUC-PR

afig@floresta.ufpr.br, Dr., Departamento de Ciências Exatas e Naturais, UNICENTRO

5 Eng. Florestal, Programa de Pós-Graduação em Engenharia Florestal, UFPR
} 
A alta qualidade da madeira do pinheiro e a grande disponibilidade da mesma nos pinhais do Sul do Brasil foram fatores importantes que contribuíram para a destruição, quase que completa, das Florestas com Araucária. Todavia, não foi a extração de madeira a principal causa da devastação iniciada no final do século passado e intensificada a partir de meados deste século. Foi sim o desmatamento para as finalidades agrícola e pecuária o grande vilão da redução da cobertura florestal nos Estados do Sul do Brasil (Sanquetta \& Tetto, 2000).

Por causa do desmatamento desenfreado, ao final da década de 70 restavam apenas $3.166 \mathrm{~km}^{2}$ dos pinhais que originalmente cobriam o Estado do Paraná, ou seja, cerca de $4,3 \%$ da área original. Segundo IBDF (1984), a área de Floresta com Araucária no Paraná foi reduzida, em 1980, para $2.696 \mathrm{~km}^{2}$. Estima-se que nas últimas duas décadas esta situação tenha ainda piorado.

Conservar os remanescentes da Floresta com Araucária é um grande desafio para o Paraná e todo o sul do Brasil. A preservação integral dos fragmentos florestais por força da lei e da fiscalização não tem sido eficaz. Apesar de todo o esforço dos órgãos oficiais e de instituições não-governamentais, os remanescentes da Floresta com Araucária têm sido objeto de perda de diversidade biológica e desestruturação, tanto do dossel como de seu sub-bosque. Essa situação tem se agravado ainda mais nos dias de hoje, pela tentativa dos proprietários rurais em substituir as áreas florestais remanescentes ditas improdutivas, por outras formas de uso do solo (Sanquetta et al, 2000).

De outro lado, assiste-se atualmente um movimento pela busca de mercados alternativos, por produtos e serviços da floresta, através da Certificação Florestal e dos chamados commodities ambientais. Essa atividade tem sido advogada como uma oportunidade impar para buscar formas diferenciadas de manejar as florestas, auferindo preços e produtos diferenciados no mercado. $\mathrm{O}$ sucesso dessas alternativas em florestas muito antropizadas como a Floresta Ombrófila Mista ainda é uma incógnita. Todavia, parece ser um alento para se buscar o almejado Manejo Sustentável.

Para buscar formas de manejar racionalmente a Floresta Ombrófila Mista, assim como outra floresta qualquer, é fundamental que se disponha de conhecimento básico sobre a estrutura e a dinâmica das populações, sobre as relações e funções ecológicas, sobre a produtividade primária, entre outros. Uma componente muito importante nesse contexto é a análise da estrutura vertical, a qual cumpre um papel fundamental nos processos ecológicos, na produção de biomassa e na coexistência das espécies (Kohyama, 1991).

Busca-se com este artigo apresentar uma caracterização da estrutura vertical em um fragmento de Floresta Ombrófila Mista na região Centro-Sul do Estado do Paraná.

\section{MATERIAIS E MÉTODOS}

\section{Descrição da área de estudo}

Este estudo foi realizado na Estação Experimental de São João do Triunfo, pertencente à Universidade Federal do Paraná, a qual situa-se a uma distância de cerca de $125 \mathrm{~km}$ de Curitiba e possui área de aproximadamente 32 ha. Seus pontos geográficos de referência são os seguintes: $25^{\circ} 34^{\prime} 18^{\prime \prime}$ latitude Sul e $50^{\circ} 05^{\prime} 56^{\prime \prime}$ longitude Oeste de Greenwich. A altitude média do local é de $780 \mathrm{~m}$.

De acordo com a classificação de Köeppen, o clima da região é do tipo $\mathrm{Cfb}$, característico de áreas planas dos planaltos (Maack, 1968). Segundo Longhi (1980), as médias de temperaturas do ar mínima, média e máxima situam-se em $12,7^{\circ} \mathrm{C}$, $17,4^{\circ} \mathrm{C}, 23,8^{\circ} \mathrm{C}$, segundo dados da Estação de Fernandes Pinheiro (IAPAR), situada nas proximidades da área de estudo. A umidade relativa do ar média anual é de $80,80 \%$, com precipitação total anual de $1591,1 \mathrm{~mm}$. O solo predominante é o argissolo vermelho amarelo distrófico, com pequena porção de cambissolo distrófico álico.

A flora autóctone caracteriza-se como Floresta Ombrófila Mista ou Floresta com Araucária (Velloso et al, 1991; IBGE, 1992). A vegetação da área de estudo apresenta a presença dominante do pinheiro (Araucaria angustifolia) e algumas espécies folhosas, como a imbuia (Ocotea porosa), 
erva-mate (Ilex paraguariensis), canelas (Lauraceae), membros da família Myrtaceae, entre outras (LONGHI, 1980). Segundo Pizatto (1999), esta floresta sofreu no passado algumas intervenções, porém ainda mantém-se bem conservada em sua composição florística e estrutura.

\section{Coleta e análise de dados}

No interior da Estação foram instaladas três unidades de um 1 ha cada, de forma quadrada $(100 \times 100 \mathrm{~m})$ e outra de forma irregular (devido à presença de um rio), com 0,5 ha, em junho de 1995. As parcelas foram locadas em função de variação nos elementos fisionômicos da vegetação. $O$ tamanho das parcelas foi baseado em recomendações feitas por Lamprecht (1964), Finol (1975), Longhi (1980), Alder (1980), Whitmore (1989), Alder \& Synnott (1992), Sanquetta (1994), Vanclay (1994) e Coraiola (1997), que recomendam parcelas grandes para levantamentos estruturais e avaliações dos processos dinâmicos em florestas naturais.

$\mathrm{Na}$ instalação das parcelas, seus perímetros foram determinados com auxílio de um teodolito. Nos vértices das parcelas e de sub-parcelas internas de $10 \times 10 \mathrm{~m}$ foram afixados piquetes de PVC, visando melhor controle. Todas as árvores com dap (diâmetro à altura do peito) igual ou superior a $10 \mathrm{~cm}$ receberam um anel pintado à altura de $1,3 \mathrm{~m}$ e etiquetas plásticas com os respectivos números das árvores. Croqui em escala foram desenhados, onde constam todos os indivíduos ocorrentes nas parcelas. Remedições dos daps das árvores foram realizadas nos anos de 1996, 1997, 1998 e 1999, sempre no inverno.

Em fevereiro de 1998, foram medidas as alturas totais 110 árvores da espécie Araucaria Angustifolia (Bert.) O. Ktze. e 97 de folhosas, com hipsômetro de Haga, em toda a área do estudo e seguindo a distribuição diamétrica da floresta.

A partir das alturas medidas e dos respectivos daps, foram desenvolvidas várias equações hipsométricas para Araucaria Angustifolia (Bert.) O. Ktze. e folhosas. As equações selecionadas para Araucaria Angustifolia (Bert.) O. Ktze. e folhosos foram, respectivamente, as seguintes:

$$
\begin{gathered}
\left(\hat{h}=\frac{-56,243247+17,575912 \cdot(\text { dap })+0,112721 \cdot(\text { dap })^{2}}{d a p}\right) \\
\left(\hat{h}=\frac{-79,852966+20,005797 \cdot(\text { dap })+0,113487 \cdot(\text { dap })^{2}}{d a p}\right)
\end{gathered}
$$

A estrutura vertical da floresta foi analisada mediante a posição sociológica das espécies. Para caracterização da posição sociológica, primeiramente lançou-se mão das relações hipsométricas previamente mencionadas (eqs. 1 e 2).

A definição do número de estratos para a floresta como um todo e para as principais populações, foi efetuada pelo Diagrama h-M, metodologia desenvolvida por Sanquetta (1995) para estratificação vertical em florestas. De acordo com os estratos definidos, calculou-se o valor da posição sociológica das espécies em função do número de árvores em cada estrato. A análise da posição sociológica foi realizada para o dados concernentes aos anos de 1995 e 1998.
No Diagrama h-M, h refere-se à altura total das árvores e $M$ representa a média cumulativa parcial da altura a partir do maior valor de $h$, dada pelo quociente da soma das alturas das árvores a partir do maior valor de $\mathrm{h}$ e da soma do número de árvores até um valor de $\mathrm{h}$ inferior ao valor máximo de h. Maiores detalhes da metodologia são encontrados em Sanquetta (1995), Coraiola (1997) e Pizatto (1999).

\section{RESULTADOS E DISCUSSÃO}

\section{Estratificação Vertical}

A figura 1 apresenta o Diagrama h$\mathrm{M}$ para a floresta como um todo (todas as espécies juntas), folhosas em separado e Araucaria Angustifolia (Bert.) O. Ktze.. 
Floresta em 1995

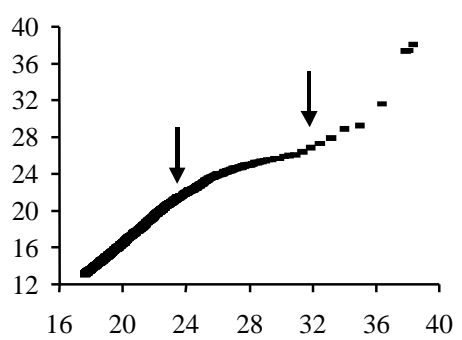

Folhosas em 1995

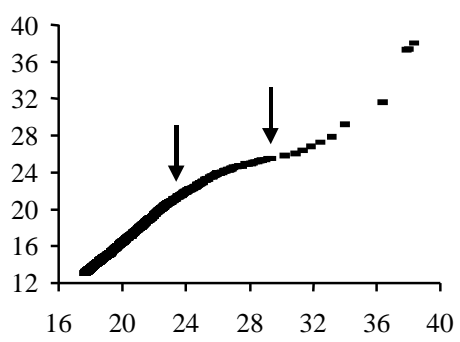

Araucaria angustifolia em 1995

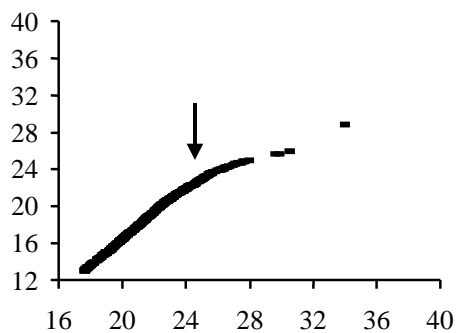

Floresta em 1998

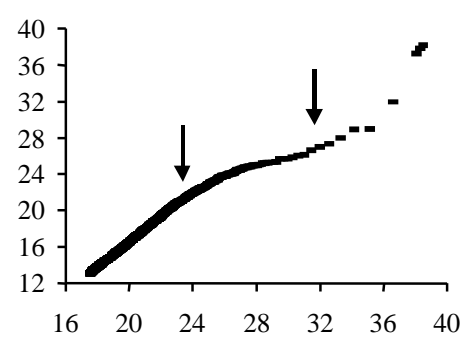

Folhosas em 1998

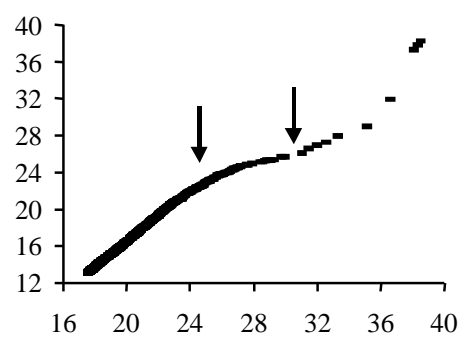

Araucaria angustifolia em 1998

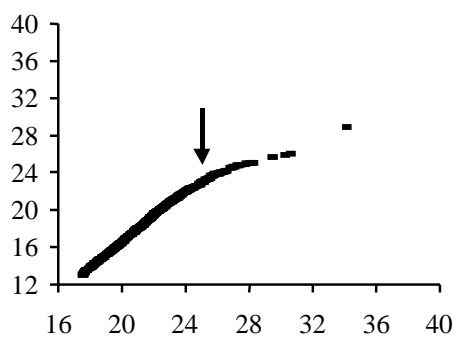

$\mathrm{M}(\mathrm{m})$

Figura 1: Estratificação segundo o diagrama $h-M$ para a floresta (todas as espécies), folhosas e Araucaria angustifolia

Figure 1: Stratification based on the h-M diagram for the forest (all species), broad-leaved and Araucaria angustifolia

Observou-se que tanto em 1995 como em 1998 a floresta apresentou 99,50\% de suas árvores com alturas inferiores a $30 \mathrm{~m}$, sendo cada ponto do diagrama correspondente a uma árvore (fig. 1). As alturas totais estimadas das árvores variaram de 13 até aproximadamente $38 \mathrm{~m}$.

Tanto em 1995 como em 1998, três estratos puderam ser reconhecidos devido à mudança no curso retilíneo no diagrama, como indicado pelas flechas. Caso tais mudanças não ocorram, significa que não existe estratificação definida. Os estratos formados podem ser contínuos ou descontínuos.

$\mathrm{O}$ primeiro estrato (estrato I), descontínuo, compõe-se de árvores acima de $27 \mathrm{~m}$ de altura e foi formado por árvores esporádicas, chamadas de emergentes ou árvores de copa alta, comuns em florestas primárias. Possivelmente estas sejam remanescentes da exploração florestal praticada no passado na área de estudo. $\mathrm{O}$ segundo estrato (estrato II), compacto e contínuo, forma-se por árvores de aproximadamente 23 a $27 \mathrm{~m}$ de altura, 
compondo o dossel superior e principal da floresta. Já o terceiro (estrato III) compõese de árvores com alturas inferiores a $23 \mathrm{~m}$, que permeiam o dossel superior e formam um estrato contínuo, compreendendo em torno de $95 \%$ do total dos indivíduos amostrados da floresta, sendo cerca de $63 \%$ das árvores com alturas entre 13 e $18 \mathrm{~m}$.

A delimitação precisa e a distinção dos vários estratos em uma floresta consiste em uma tarefa difícil. O Diagrama h-M mostrou ser um método que permite separar estratos naturas de altura na floresta, evitando critérios arbitrários normalmente empregados em estratificação.

Araucaria Angustifolia caracterizase por ser uma espécie que atinge grande porte e encontra-se também regularmente distribuída ao longo do perfil vertical da floresta. Essa espécie apresentou a maior concentração dos indivíduos ( $82 \%$ do total) com alturas menores que $22 \mathrm{~m}$, parte das árvores do dossel (13\%) com alturas entre 22 a 24 m, e algumas árvores isoladas (4\%) com alturas superiores a estes valores. A maioria das árvores (45\%) desta espécie apresentou alturas entre 18 e $22 \mathrm{~m}$, diferindo das folhosas em que a grande maioria $(72 \%)$ apresentou alturas entre $13 \mathrm{e}$ $18 \mathrm{~m}$.

\section{Posição Sociológica}

Das 65 espécies identificadas em 1995 (tab. 1), apenas cinco apresentaram indivíduos emergentes (com alturas superiores a $27 \mathrm{~m}$ ). A espécie imbuia (Ocotea porosa) dominou este estrato com 3 ind./3,5ha, canela-guaicá (Ocotea puberula) com 2 ind. $/ 3,5$ ha, em seguida, as espécies Araucaria Angustifolia, açoita- cavalo (Luehea divaricata.) e canelacoqueiro (Ocotea sp.) encontraram-se representadas com apenas 1 ind./3,5ha (tab. 2).

Destas cinco espécies previamente citadas, quatro (Ocotea porosa, Ocotea puberula, Araucaria Angustifolia e Luehea divaricata), ou seja, $6,15 \%$ do número total de espécies, apresentaram árvores distribuídas nos três estratos definidos da floresta.

As seis espécies com maior posição sociológica da floresta, em termos de número de indivíduos em cada estrato em 1995, representaram mais de $50 \%$ do total desse parâmetro e são as que se encontram entre as mais abundantes da população.

Araucaria Angustifolia apresentou maior posição sociológica $(24,91 \%)$, possuindo indivíduos nos três estratos definidos na floresta, cujo maior número de árvores concentrou-se nos estratos II (altura entre 23 e $27 \mathrm{~m}$ ) e III (com alturas inferiores a $23 \mathrm{~m}$ ). Esta espécie apresentou também os maiores valores de posição sociológica nas parcelas 2, 3 e 4 .

A segunda espécie de maior posição sociológica da floresta foi canelaamarela (Nectandra grandiflora) com $9,80 \%$. Esta espécie não apresentou indivíduos no estrato I, com poucos indivíduos no estrato II e a grande maioria das árvores encontrou-se representada no estrato III, sendo a segunda com maior posição sociológica nas parcelas 2,3 e 4 .

Em 1998 houve pouca alteração em termos de posição sociológica das espécies na floresta como um todo, como pode ser observado na tabela 3 . 
Tabela 1: Lista de espécies ocorrentes na área de estudo

Table 1: $\quad$ Species list of the study site

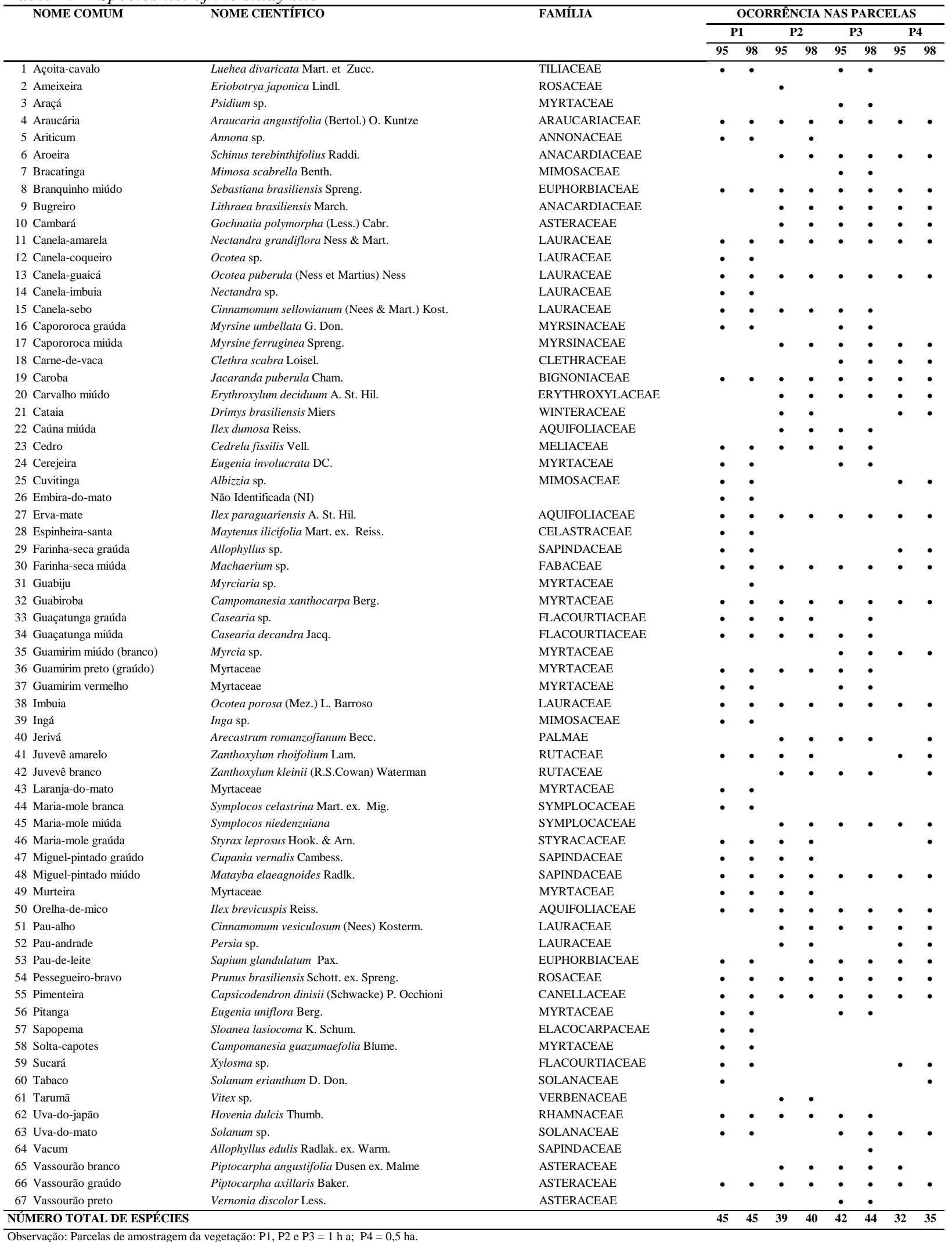


Estrutura vertical de um...

Tabela 2: Número de árvores por estrato e posição sociológica absoluta por parcela e relativa para o total da floresta em 1995

Table 2: $\quad$ Number of trees per stratum and absolute and relative social position per plot for the whole forest in 1995

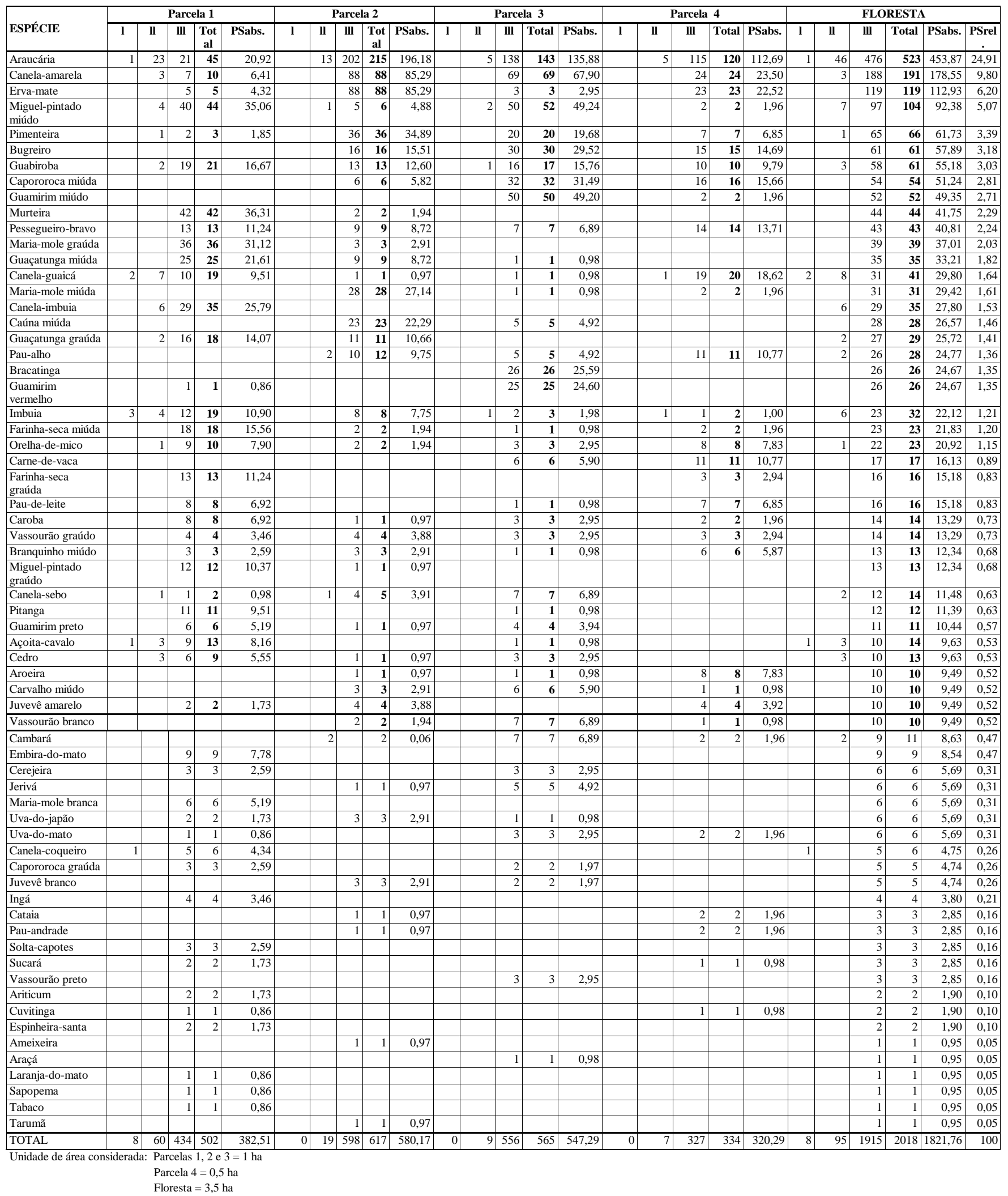


Tabela 3: $\quad$ Número de árvores por estrato e posição sociológica absoluta por parcela e relativa para o total da floresta em 1998

Table 3: $\quad$ Number of trees per stratum and absolute and relative social position per plot for the whole forest in 1998

\begin{tabular}{|c|c|c|c|c|c|c|c|c|c|c|c|c|c|c|c|c|c|c|c|c|c|c|c|c|c|}
\hline \multirow{2}{*}{ ESPÉCIE } & \multicolumn{5}{|c|}{ Parcela 1} & Parcela 2 & & & & & rcela 3 & 3 & & & Parc & cela 4 & & & & FLC & $\overline{\text { OREST }}$ & & & & \\
\hline & 1 & Ll & III & Tot & PS abs. & \begin{tabular}{|l|l|l|l} 
II & I \\
\end{tabular} & III & Tot & PS abs. & 1 & II & III & Tot & PS abs. & 1 & II & III & Tot & Ps abs. & 1 & II & III & Tot & PS abs. & PS rel. \\
\hline Araucária & 1 & 24 & 20 & 45 & 20,19 & $\overline{142}$ & 200 & 214 & 193,63 & & 5 & 139 & 144 & 101,27 & & 7 & 117 & 124 & 114,71 & 1 & 50 & 476 & 527 & 454,12 & 23,50 \\
\hline Canela-amarela & & 3 & 8 & 11 & 7,28 & & 102 & 102 & 98,51 & & & 74 & 74 & 53,87 & & & 27 & 27 & 26,44 & & 3 & 211 & 214 & 200,39 & 10,37 \\
\hline Erva-mate & & & 5 & 5 & 4,32 & & 97 & 97 & 93,68 & & & 3 & 3 & 2,18 & & & 29 & 29 & 28,40 & & & 134 & 134 & 127,17 & 6,58 \\
\hline $\begin{array}{l}\text { Miguel-pintado } \\
\text { miúdo }\end{array}$ & & 6 & 40 & 46 & 35,30 & 1 & 5 & 6 & 4,86 & & 3 & 51 & 54 & 37,18 & & & 6 & 6 & 5,88 & & 10 & 102 & 112 & 97,28 & 5,03 \\
\hline Pimenteira & & 1 & 3 & 4 & 2,71 & & 36 & 36 & 34,77 & & & 20 & 20 & 14,56 & & & 7 & 7 & 6,85 & & 1 & 66 & 67 & 62,69 & 3,24 \\
\hline Capororoca miúda & & & & & & & 4 & 4 & 3,86 & & & 42 & 42 & 30,58 & & & 17 & 17 & 16,65 & & & 63 & 63 & 59,79 & 3,09 \\
\hline Guabiroba & & 2 & 23 & 25 & 20,13 & & 12 & 12 & 11,59 & & 1 & 16 & 17 & 11,66 & & & 10 & 10 & 9,79 & & 3 & 61 & 64 & 58,03 & 3,00 \\
\hline Bugreiro & & & & & & & 8 & 8 & 7,73 & & & 33 & 33 & 24,02 & & & 14 & 14 & 13,71 & & & 55 & 55 & 52,20 & 2,70 \\
\hline Guamirim miúdo & & & & & & & & & & & & 52 & 52 & 37,86 & & & 2 & 2 & 1,96 & & & 54 & 54 & 51,25 & 2,65 \\
\hline Murteira & & & 51 & 51 & 44,09 & & 2 & 2 & 1,93 & & & & & & & & & & & & & 53 & 53 & 50,30 & 2,60 \\
\hline Pessegueiro-bravo & & & 13 & 13 & 11,24 & & 12 & 12 & 11,59 & & & 9 & 9 & 6,55 & & & 17 & 17 & 16,65 & & & 51 & 51 & 48,40 & 2,50 \\
\hline Canela-guaicá & 2 & 5 & 9 & 16 & 8,41 & & 1 & $\mathbf{1}$ & 0,97 & & & 2 & 2 & 1,46 & & & 28 & 28 & 27,42 & 2 & 5 & 40 & 47 & 38,21 & 1,98 \\
\hline Maria-mole graúda & & & 35 & 35 & 30,26 & & 4 & 4 & 3,86 & & & ( & & & & & 1 & 1 & 0,98 & & & 40 & 40 & 37,96 & 1,96 \\
\hline Pau-alho & & & & & & 3 & 10 & 13 & 9,76 & & & 8 & 8 & 5,82 & & & 18 & 18 & 17,63 & & 3 & 36 & 39 & 34,31 & 1,78 \\
\hline Guaçatunga miúda & & & 23 & 23 & 19,89 & & 9 & 9 & 8,69 & & & 2 & 2 & 1,46 & & & & & & & & 34 & 34 & 32,27 & 1,67 \\
\hline Guamirim vermelho & & & 1 & 1 & 0,86 & & & & & & & 31 & 31 & 22,57 & & & & & & & & 32 & 32 & 30,37 & 1,57 \\
\hline Canela-imbuia & & 7 & 28 & 35 & 26,78 & & & & & & & & & & & & & & & & 7 & 28 & 35 & 28,80 & 1,49 \\
\hline Guaçatunga graúda & & 2 & 14 & 16 & 12,34 & & 13 & 13 & 12,55 & & & 2 & 2 & 1,46 & & & & & & & 2 & 29 & 31 & 27,62 & 1,43 \\
\hline Bracatinga & & & & & & & & & & & & 28 & 28 & 20,38 & & & & & & & & 28 & 28 & 26,57 & 1,38 \\
\hline Orelha-de-mico & & 1 & 9 & 10 & 7,90 & & 1 & 1 & 0,97 & & & 5 & 5 & 3,64 & & & 10 & 10 & 9,79 & & 1 & 25 & 26 & 23,77 & 1,23 \\
\hline Farinha-seca miúda & & & 18 & 18 & 15,56 & & 2 & 2 & 1,93 & & & 1 & 1 & 0,73 & & & 2 & 2 & 1,96 & & & 23 & 23 & 21,83 & 1,13 \\
\hline Carne-de-vaca & & & & & & & & & & & & 6 & 6 & 4,37 & & & 16 & 16 & 15,67 & + & & 22 & 22 & 20,88 & 1,08 \\
\hline Imbuia & 3 & 3 & 12 & 18 & 9,05 & & 8 & 8 & 7,73 & & 1 & 2 & 3 & 1,47 & & 1 & 1 & 2 & 1,00 & 3 & 5 & 23 & 31 & 20,18 & 1,04 \\
\hline Maria-mole miúda & & & & & & & 16 & 16 & 15,45 & & & 2 & 2 & 1,46 & & & 3 & 3 & 2,94 & & & 21 & 21 & 19,93 & 1,03 \\
\hline Caúna miúda & & & & & & & 14 & 14 & 13,52 & & & 4 & 4 & 2,91 & & & & & & & & 18 & 18 & 17,08 & 0,88 \\
\hline Canela-sebo & & 1 & 2 & 3 & 1,85 & 1 & 4 & 5 & 3,90 & & & 11 & 11 & 8,01 & & & & & & & 2 & 17 & 19 & 16,23 & 0,84 \\
\hline Pau-de-leite & & & 8 & 8 & 6,92 & & 1 & 1 & 0,97 & & & 1 & $\mathbf{1}$ & 0,73 & & & 7 & 7 & 6,85 & & & 17 & 17 & 16,13 & 0,83 \\
\hline Pitanga & & & 14 & 14 & 12,10 & & & & & & & 1 & 1 & 0,73 & & & & & & & & 15 & 15 & 14,24 & 0,74 \\
\hline Branquinho miúdo & & & 3 & 3 & 2,59 & & 3 & 3 & 2,90 & & & 1 & 1 & 0,73 & & & 7 & 7 & 6,85 & & & 14 & 14 & 13,29 & 0,69 \\
\hline Caroba & & & 8 & 8 & 6,92 & & 1 & 1 & 0,97 & & & 3 & 3 & 2,18 & & & 2 & 2 & 1,96 & & & 14 & 14 & 13,29 & 0,69 \\
\hline Farinha-seca graúda & & & 11 & 11 & 9,51 & & & & & & & & & & & & 3 & 3 & 2,94 & & & 14 & 14 & 13,29 & 0,69 \\
\hline $\begin{array}{l}\text { Miguel-pintado } \\
\text { graúdo }\end{array}$ & & & 13 & 13 & 11,24 & & 1 & 1 & 0,97 & & & & & & & & & & & & & 14 & 14 & 13,29 & 0,69 \\
\hline Vassourão graúdo & & & 3 & 3 & 2,59 & & 4 & 4 & 3,86 & & & 4 & 4 & 2,91 & & & 3 & 3 & 2,94 & & & 14 & 14 & 13,29 & 0,69 \\
\hline Jerivá & & & & & & & 2 & 2 & 1,93 & & & 9 & 9 & 6,55 & & & 2 & 2 & 1,96 & & & 13 & 13 & 12,34 & 0,64 \\
\hline Guamirim preto & & & 7 & 7 & 6,05 & & 1 & 1 & 0,97 & & & 4 & 4 & 2,91 & & & & & & & & 12 & 12 & 11,39 & 0,59 \\
\hline Cedro & & 3 & 6 & 9 & 5,55 & 1 & & 1 & 0,03 & & & 5 & 5 & 3,64 & & & & & & & 4 & 11 & 15 & 10,63 & 0,55 \\
\hline Juvevê amarelo & & 1 & 1 & 2 & 0,98 & & 3 & 3 & 2,90 & & & + & & & & & 7 & 7 & 6,85 & 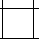 & 1 & 11 & 12 & 10,49 & 0,54 \\
\hline Açoita-cavalo & 1 & 3 & 9 & 13 & 8,16 & & & & & & & 1 & 1 & 0,73 & & & & & & 1 & 3 & 10 & 14 & 9,64 & 0,50 \\
\hline Cambará & & & & & & 1 & & 1 & 0,03 & & & 9 & 9 & 6,55 & & & 1 & 1 & 0,98 & & 1 & 10 & 11 & 9,54 & 0,49 \\
\hline Aroeira & & & & & & & 1 & 1 & 0,97 & & & 1 & 1 & 0,73 & & & 8 & 8 & 7,83 & & & 10 & 10 & 9,49 & 0,49 \\
\hline Carvalho miúdo & & & & & & & 3 & 3 & 2,90 & & & 5 & 5 & 3,64 & & & 2 & 2 & 1,96 & & & 10 & 10 & 9,49 & 0,49 \\
\hline Embira-do-mato & & & 10 & 10 & 8,65 & & & & & & & & & & & & & & & & & 10 & 10 & 9,49 & 0,49 \\
\hline Uva-do-japão & & & 2 & 2 & 1,73 & & 3 & 3 & 2,90 & & & 4 & 4 & 2,91 & & & & & & & & 9 & 9 & 8,54 & 0,44 \\
\hline Vassourão branco & & & & & & & 2 & 2 & 1,93 & & & 7 & 7 & 5,10 & & & & & & & & 9 & 9 & 8,54 & 0,44 \\
\hline Uva-do-mato & & & 1 & 1 & 0,86 & & & & & & & 5 & 5 & 3,64 & & & 2 & 2 & 1,96 & & & 8 & 8 & 7,59 & 0,39 \\
\hline Maria-mole branca & & & 7 & 7 & 6,05 & & & & & & & & & & & & & & & & & 7 & 7 & 6,64 & 0,34 \\
\hline Capororoca graúda & & & 4 & 4 & 3,46 & & & & & & & 2 & 2 & 1,46 & & & & & & & & 6 & 6 & 5,69 & 0,29 \\
\hline Cerejeira & & & 3 & 3 & 2,59 & & & & & & & 3 & 3 & 2,18 & & & & & & & & 6 & 6 & 5,69 & 0,29 \\
\hline Canela-coqueiro & 1 & & 5 & 6 & 4,34 & & & & & & & & & & & & & & & 1 & & 5 & 6 & 4,75 & 0,25 \\
\hline Pau-andrade & & & & & & & 3 & 3 & 2,90 & & & & & & & & 2 & 2 & 1,96 & & & 5 & 5 & 4,75 & 0,25 \\
\hline Ingá & & & 4 & 4 & 3,46 & & & & & & & & & & & & & & & & & 4 & 4 & 3,80 & 0,20 \\
\hline Juvevê branco & & & & & & & 1 & 1 & 0,97 & & & 2 & 2 & 1,46 & & & 1 & 1 & 0,98 & & & 4 & 4 & 3,80 & 0,20 \\
\hline Ariticum & & & 2 & 2 & 1,73 & & 1 & 1 & 0,97 & & & & & & & & & & & & & 3 & 3 & 2,85 & 0,15 \\
\hline Cataia & & & & & & & 1 & 1 & 0,97 & & & & & & & & 2 & 2 & 1,96 & & & 3 & 3 & 2,85 & 0,15 \\
\hline Sapopema & & & 3 & 3 & 2,59 & & & & & & & & & & & & & & & & & 3 & 3 & 2,85 & 0,15 \\
\hline Solta-capotes & & & 3 & 3 & 2,59 & & & & & & & & & & & & & & & & & 3 & 3 & 2,85 & 0,15 \\
\hline Sucará & & & 2 & 2 & 1,73 & & & & & & & & & & & & 1 & 1 & 0,98 & & & 3 & 3 & 2,85 & 0,15 \\
\hline Vassourão preto & & & & & & & & & & & & 3 & 3 & 2,18 & & & & & & & & 3 & 3 & 2,85 & 0,15 \\
\hline Cuvitinga & & & 1 & 1 & 0,86 & & & & & & & & & & & & 1 & 1 & 0,98 & & & 2 & 2 & 1,90 & 0,10 \\
\hline Araçá & & & & & & & & & & & & 1 & 1 & 0,73 & & & & & & & & 1 & 1 & 0,95 & 0,05 \\
\hline Espinheira-santa & & & 1 & 1 & 0,86 & & & & & & & & & & & & & & & & & 1 & 1 & 0,95 & 0,05 \\
\hline Guabiju & & & 1 & 1 & 0,86 & & & & & & & & & & & & & & & & & 1 & 1 & 0,95 & 0,05 \\
\hline Laranja-do-mato & & & 1 & 1 & 0,86 & & & & & & & & & & & & & & & & & 1 & 1 & 0,95 & 0,05 \\
\hline Tabaco & & & & & & & & & & & & & & & & & 1 & 1 & 0,98 & & & 1 & 1 & 0,95 & 0,05 \\
\hline Tarumã & & & & & & & 1 & 1 & 0,97 & & & & & & & & & & & & & 1 & 1 & 0,95 & 0,05 \\
\hline Vacum & & & & & & & & & & & & 1 & 1 & 0,73 & & & & & & . & & 1 & 1 & 0,95 & 0,05 \\
\hline TOTAL & 8 & 62 & 447 & 517 & \begin{tabular}{l|l|}
394,04 \\
\end{tabular} & \begin{tabular}{l|l|l}
0 & 21 & 5
\end{tabular} & 592 & 613 & 572,44 & 0 & 10 & 455 & 625 & 331,40 & 0 & 8 & 377 & 385 & 369,33 & $\overline{8}$ & 101 & 2031 & 2140 & 1932,3 & 100 \\
\hline
\end{tabular}


Das 66 espécies encontradas, quatro $(6,06 \%)$ apresentaram indivíduos nos estratos I, II e III; 13 espécies $(19,70 \%)$ apresentaram-se em dois estratos (12 nos estratos II e III, e uma, Ocotea $s p$., nos estratos I e III). A maioria, 49 espécies $(74,24 \%)$, apresentou indivíduos apenas no estrato III.

Das seis espécies que representaram mais de $50 \%$ da posição sociológica, Araucaria angustifolia, tanto em 1998 como em 1995, foi a espécie que apresentou maior valor $(23,50 \%)$ deste parâmetro.

\section{CONCLUSÕES}

Após as constatações desta pesquisa, concluiu-se o que segue:

- Diagrama $h-M$ indicou a existência de três estratos verticais na floresta como um todo, três estratos definidos para folhosas e dois para Araucaria angustifolia. Constatou-se a presença de estratos bem definidos para algumas populações, enquanto que para outras não. O Diagrama $h$ - $M$ mostrou ser uma metodologia simples e prática que permitiu o reconhecimento de estratos naturais na floresta;

- As espécies que apresentaram maiores valores de posição sociológica na floresta foram: Araucaria angustifólia, Nectandra grandiflora e Ilex paraguariensis, totalizando $39,62 \%$ do total da floresta. Araucaria angustifolia encontrou-se distribuída nos três estratos definidos para a floresta como um todo, Nectandra grandiflora em dois e Ilex paraguariensis encontrou-se em apenas um estrato. Os altos valores da posição sociológica são explicados pela alta concentração dos indivíduos no estrato inferior da floresta;

- No período de 3 anos (de 1995 a 1998) houve pouca alteração na estrutura vertical da floresta em apreço.

\section{AGRADECIMENTOS}

Os autores agradecem a diversos professores e alunos da UFPR, que ao longo de vários auxiliaram na coleta anual de dados. Agradecimento especial ao Prof. Carlos Vellozo Roderjan (UFPR) e ao cientista Dr. Gerdt Hatschbach (Museu Municipal de Curitiba), que contribuíram na identificação de espécies.

\section{REFERÊNCIAS}

ALDER, D. Estimación del volumen forestal y predicción del rendimiento con especial referencia a los trópicos. Tomo II Predicción del rendimiento. Roma: FAO 22/2, 1980. 118p.

ALDER, D.; SYNNOTT, T.J. Permanent sample plot techniques for mixed tropical forest. Oxford Forestry Institute. University of Oxford. Tropical Forestry Papers 25, 1992. 124p.

CORAIOLA, M. Caracterização estrutural de uma Floresta Estacional Semidecidual localizada no município de Cássia - MG. Dissertação. M Mestrado em Ciências Florestais. Curitiba: Universidade Federal do Paraná, 1997. 196p.

FINOL, U.H. La silvicultura en la Orinoquia Venezolana. Rev. For. Venez., v. 18, n. 25, p. 37-114, 1975.

IBDF - INSTITUTO BRASILEIRO DE DESENVOLVIMENTO FLORESTAL. Inventário Nacional. Florestas Nativas Paraná e Santa Catarina. Brasília, 1984. 345p.

IBGE - INSTITUTO BRASILEIRO DE GEOGRAFIA E ESTATÍSTICA. Vegetação e geografia do Brasil - Região Sul. Rio de Janeiro, 1990. v. 2. 419p.

IBGE - INSTITUTO BRASILEIRO DE GEOGRAFIA E ESTATÍSTICA. Manual técnico da vegetação brasileira. Rio de Janeiro, 1992. 92 p.

KOHYAMA, T. Simulating stationary size distribution of trees in rain forests. Annals of Botany, v. 68, p. 173-180, 1991.

LAMPRECHT, H. Ensayo sobre estructura florística de la parte sur-oriental del Bosque Universitario "El Caimital" Estado Barinas. Rev. For. Venez., v. 7, n. 10/11, p. 77-119, 1964.

LONGHI, S.J. A estrutura de uma floresta natural de Araucaria Angustifolia (Bert.) O. Ktze, no sul do Brasil. Dissertação. Mestrado em Ciências Florestais. Curitiba: Universidade Federal do Paraná, 1980. 198p.

MAACK, R. Geografia física do Estado do Paraná. Curitiba: CODEPAR, 1968. 350p. 
PIZATTO, W. Avaliação biométrica da estrutura e da dinâmica de uma Floresta Ombrófila Mista em São João do Triunfo-PR: 1995 a 1998. Dissertação. Mestrado em Ciências Florestais. Curitiba: Universidade Federal do Paraná. 1999, 170p.

SANQUETTA, C.R. A model of natural regeneration process of a fir-hemlock, southwestern Japan. Tese. Doutorado em Recursos Florestais. Matsuyama, Japão: Universidade de Ehime. 1994. 136p.

SANQUETTA, C.R Análise da estrutura vertical de florestas através do diagrama $h-$ M. Ciência Florestal, v. 5, n. 1., p. 55-68, 1995.

SANQUETTA, C.R.; PIZATTO, W.; PÉLLICO-NETTO, S.; FIGUEIREDO FILHO, A. Dinâmica da composição florística de um fragmento de Floresta Ombrófila Mista no Centro-Sul do Paraná. Revista Ciências Exatas e Naturais, v.1, n.2, p.77-88. 2000.
SANQUETTA, C.R.; TETTO, A.F. Pinheiro-do-Paraná: Lendas e Realidades. Curitiba: FUPEF do Paraná. 2000. 112p.

VANCLAY, J.K. Modelling forest growth and yield - applications to mixed tropical forests. Wallingford: CAB International, 1994. 312p.

VELLOZO, H.P.; RANGEL FILHO, A.L.R. \& LIMA, J.C.A. Classificação da vegetação brasileira, adaptada a um sistema universal. Rio de Janeiro: Fundação IBGE, 1991. 123p.

WHITMORE, T.C. An introduction to tropical rain forests. Oxford: Clarendon Press, 1989. 226 